\title{
Developments and Progress in Non-contact Eye Tonometer Calibration
}

\author{
Peter Pavlásek $^{1}$, Jan Rybář ${ }^{2}$, Stanislav Duriš² ${ }^{2}$ Branislav Hučko $^{2}$, Miroslav Chytil ${ }^{3}$, Alena Furdová ${ }^{4}$, \\ Sylvia Lea Ferková ${ }^{4}$, Juraj Sekáč ${ }^{4}$, Vítězslav Suchý ${ }^{5}$, Patrik Grosinger ${ }^{2}$ \\ ${ }^{1}$ Faculty of Mechanical Engineering, Slovak university of Technology, Námestie slobody 17, 812 31, Bratislava 1, Slovakia, \\ and Slovak Institute of Metrology, Karloveská 63, 842 55, Bratislava 4, Slovakia, peterpavlasek@gmail.com \\ ${ }^{2}$ Faculty of Mechanical Engineering, Slovak university of Technology, Námestie slobody 17, 812 31, Bratislava 1, Slovakia, \\ jan.rybar@stuba.sk \\ ${ }^{3}$ Slovak Institute of Metrology, Karloveská 63, 842 55, Bratislava 4, Slovakia \\ ${ }^{4}$ Department of Ophthalmology, Faculty of Medicine, Comenius University in Bratislava, Hospital Ružinov, Ružinovská 6, \\ 82606, Bratislava, Slovakia \\ ${ }^{5}$ Regional Inspectorate Most, Czech Metrology Institute, Vladislava Vančury 1428/7, 434 01, Most, Czech Republic
}

\begin{abstract}
This paper focuses on the problematic of intraocular pressure (IOP) measurements, performed by non-invasive methods. More specifically, the devices that are connected with the presented finding are non-contact tonometers that use concentrated air stream and optical sensors to determine the IOP within a human's eye. The paper analyzes various influential factors that have an effect on the determination of the IOP values originating from the patients themselves and from the non-contact tonometer devices. The paper furthermore elaborates on the lack of independent methods of calibration and control of these devices. In order to fill this gap a measurement standard device that is capable of calibrating and testing these devices with traceability to the basic SI unit is presented. A detailed characterization and the determination of the expected uncertainty of the device are provided. By introducing an independent and traceable calibration method and control of noncontact tonometers into the clinical practice, the reliability of the measured IOP that is the primary indicator of glaucoma can be improved.
\end{abstract}

Keywords: Glaucoma; tonometry; IOP measurements; non-contact; calibration; standard.

\section{INTRODUCTION}

Glaucoma is a major global cause of blindness responsible for $37.5 \%$ of all blind people in the world according to the studies of the World Health Organization (WHO) [1], [2]. As eye pressure measurements are essential for the prevention of this disease, it is of great importance to have reliable and precise measurements of the intraocular pressure (IOP). These measurements can be done by two main approaches: contact method and non-contact methods. In this paper we will be focusing on the non-contact tonometers that have gained a significant popularity in recent years. Non-contact tonometers are one of the most used IOP measuring devices today. They are fast, easy to use and provide a better level of comfort to the patient in comparison with traditional contact eye tonometer devices [3]-[12], [23]. Unfortunately, these advantages are overshadowed by the lack of precision and ability of an independent metrological calibration, which can result in imprecise measurement that will affect diagnostics and the subsequent treatment of glaucoma.
The basic issue for all types of IOP non-contact measuring devices is currently the missing universal standard for the purpose of calibration and control that could be applied to measuring devices from all manufacturers. Currently, the variety of approaches to measure the IOP, together with the use of manufacturer in house made standards, which are made solely for their specific device, makes an objective and traceable calibration from the view of metrology, difficult. This lack of an independently designed universal calibration device makes the comparison of measured IOP between devices challenging, if not impossible. The ability to compare measurement results is of great importance when patients' measured IOP differs from device to device (from various manufacturers). This problem emerges mainly in the non-contact tonometers, but with the ever more decreasing use of contact methods that are time consuming for the medical professionals and uncomfortable for the patient, it gains on importance.

The calibration standard that is going to be presented within this paper is designed with the goal to address the 
issues raised in previous sections. This newly designed standard consists of two main parts. One part of this measurement setup is responsible for the pressure generation, which is based on a piston pressure generator and a second part that consists of a pressure chamber with an artificial cornea. The geometry and material properties of the artificial cornea are designed and selected in such a way to best mimic the human eye. A more detailed description of the design, basic principle of function and initial test results of a potential calibration standard that is capable of delivering calibration of non-contact tonometers with traceability to the basic SI unit is presented within the upcoming sections.

\section{INFLUENTIAL FACTORS ON NON-CONTACT IOP MEASUREMENTS}

The factors influencing the measurement of the intraocular pressure (IOP) can be divided into two groups. The first group includes those factors, which affect the interaction of the eye with the measuring device. In this case the measured IOP is not equal to the "real" IOP in the eye. These factors are closely connected to the principle of the used measuring method and the used measurement device. The second group of factors influencing the IOP is connected to the properties of eye tissue, eye geometry and patient's current health state.

In order to understand the possible risks that non-contact tonometry brings, we must understand the basic principles of their function. Non-contact tonometers are a type of applanation tonometers where the applanation is realized by an air-puff, i.e. without direct contact with the cornea. The pressure caused by the puff is increased until the cornea is applanated over a predetermined area. The applanation is determined by optical means, by the use of an IR (Infrared) light source of various wavelengths (based on manufacturer) that reaches a dedicated detector when the eye surface is flattened [17], [23].

The IOP value is calculated by the device based on the time it takes the puff of air to create the cornea applanation. During this process, the time of the applanation is recorded. This is done by an accurate built in clock that is capable of measuring time in thousandth of a second. In further detail the intraocular pressure of the measured object (in this case the eye) is calculated from the time that has passed since the initial air puff, up until the corneal application is achieved and from the air pressure that caused the flattening (applanation). Using this data, the device determines the IOP, which can be described by the equation:

$$
\frac{d V}{d t}=R \cdot\left(p_{\mathrm{v}}-I O P_{m}\right)
$$

Where $I O P_{m}$ is the measured intraocular pressure with a non-contact eye tonometer, $R$ indicates the corneal stiffness or rigidity, $p_{\mathrm{v}}$ is the air pressure pressing on the cornea (equivalent to approximately $10.66 \mathrm{kPa} \approx 80 \mathrm{mmHg}$ ) and $d V$ is then the change in the internal volume of the eye during the observed time $d t$. Using this equation the $I O P_{m}$ can be expressed by the equation (2). [18], [19], [23]

$$
I O P_{m}=p_{\mathrm{v}}-\frac{1}{R} \cdot \frac{d V}{d t}
$$

Based on the previously described measurement principle we can assume the following potential influential factors. Influential factors that have a less significant effect on the IOP measurements are the exact measurement of time and air pressure generation (specifically its consistency). The potentially more significant effect is the determination of the distance of the air stream source from the eye and the repeatability of the ideal distance. The most severe factor is without a doubt the evaluation method that determines the IOP pressure. The manufacturers use undisclosed algorithms to calculate the IOP from multiple quantities (pressure, time, corneal stiffness, etc.). This leaves a significant grey area for error in the calculation of the "true" IOP value. Based on the previously mentioned technical factors that affect the noncontact measurements of IOP, the need for a reference standard to check and calibrate these devices is evident and much desired.

\section{CURRENT REFERENCE STANDARD ISSUES}

The intraocular pressure is an important parameter for determining pathological phenomena. The value of intraocular pressure is defined by the ratio between the rate of formation and the outflow of the intraocular fluid. We consider a state during which no damage of the optic nerve occurs under constant conditions inside the eye as normal intraocular pressure. If the dynamic of the intraocular fluid in the eye does not maintain a stable volume then the intraocular pressure is not stable and poor drainage pathway and accumulation of intraocular fluid occurs, which causes an increase of the intraocular pressure [13], [23]. The casual values of intraocular pressure of an adult individual are usually in the range from $11 \mathrm{mmHg}$ to $21 \mathrm{mmHg}$. Values above $21 \mathrm{mmHg}$ are considered as high and a significant factor that can cause glaucoma. The danger of this disease is primarily that the patient does not sense any symptoms in its initial stages.

Repeated routine measurements of IOP of a patient have shown inconsistencies of the measured values, both in long term and short term measurements. These changing values of IOP have been observed on the same measurement device but also with the use of different types of devices. In order to be confident of the measured values that were indicated by the tonometer we must be able to independently calibrate/check these devices with an associated measurement uncertainty. At the moment proper function of a tonometer is checked by portable standards that are designed by the manufacturers for their specific device type. Based on this approach there are numerous standards and procedures that are used to check the correct function of tonometers. These can be currently used with a restricted number of devices from one manufacturer. Further issues arise from the fact that these standard devices have not undergone an independent testing that would define critical metrological parameters like: repeatability, stability, and hysteresis. Although in general the standards function and IOP values generation are checked by using a clinically tested tonometer, it does not confirm the validity of the standards' own metrological parameters. This is mainly due to the fact that the standards function is checked basically by 
the same device that it should check/calibrate and it does not take into account other factors that affect the measurements of the tonometer itself. In addition, most of the commonly used standards do not have their measurement uncertainty determined and lack the traceability to the basic SI unit. Due to these points it is important to have a universal standard with well-defined measurement uncertainty that would enable the comparison of different devices, to determine measurement uncertainty and to create traceability to the basic SI unit [13], [14].

\section{REFERENCE STANDARD DEVELOPMENT}

The reason for the use and development of a portable standard is to ensure that the indicated value of the intraocular pressure by a tonometer that is used in medical practice is reliable throughout its use. This is of high importance during patient diagnostic, as one higher value of intraocular pressure does not have to refer to a glaucoma disease, but this value must be considered and monitored in the future in the patient's upcoming physical examination. This could result in a false diagnosis if the device developed a drift that would be left undetected.

As was shown on this example, it is of high importance to have a portable, reliable and traceable standard to perform calibrations and control of non-contact eye tonometers. This demand has led us to the development of a new standard that is both traceable to the basic SI unit (in this specific case $\mathrm{kg}$ ) and has the potential to be universally used on any eye noncontact tonometer.

The measuring apparatus consists of a portable calibration standard with eye model. In more detail the standard is composed of a pressure piston filled with fluid (demineralized water), connectors, T-shaped stand with two screws for precise eye model attachment, height-adjustable eye model with replaceable material (artificial cornea), and a pressure gauge [15], [23]. The measurement setup can be seen in Fig.1. and Fig.2.

The use of a piston together with weights enables the traceability to the SI and furthermore provides a stable and highly repeatable pressure generation. The calculated pressure generated uncertainty by this specific method was determined to be $0.2 \mathrm{mmHg}(0.026 \mathrm{kPa})$. This low level of uncertainty makes the generated pressure a reliable source of stable values of pressure which is translated to the artificial cornea.

The basic principle of the developed standard is that the pressure generated by a piston is transferred via liquid (demineralized water) to the pressure chamber with an artificial cornea. This chamber is then put on the measuring stand of the tonometer instead of the patient, as can be seen in Fig.1. The pressure from the lowest to the upper limits of the device under test is then generated and measured with the tonometer on the standard as during a routine IOP measurement.

The generated pressure $p$ that is applied to the surface of the artificial cornea can be calculated based on the equation:

$$
p=p_{\mathrm{v}}+p_{\mathrm{p}}=h \cdot \rho_{\mathrm{H}_{2} 0} \cdot g+\frac{4\left(m_{\mathrm{C}}+m\right) g}{\pi \cdot d^{2}}(\mathrm{~Pa})
$$

Where $p_{\mathrm{v}}$ is the pressure generated by a level of liquid $h$ of a specific density (in this case water) $\rho_{\mathrm{H} 20}$ under gravitational acceleration $g$. This pressure can be expressed by the equation (4).

$$
p_{\mathrm{v}}=h \cdot \rho_{\mathrm{H}_{2} 0} \cdot g(\mathrm{~Pa})
$$

The pressure $p_{\mathrm{p}}$ represents the contribution originating from the surface of the cylinder $S$ and from the cylinder's own weight $\left(m_{\mathrm{C}}\right)$ and added weight $(m) G$. The resulting pressure is determined by the equation:

$$
p_{\mathrm{p}}=\frac{G}{S}=\frac{4\left(m_{\mathrm{C}}+m\right) g}{\pi \cdot d^{2}}(\mathrm{~Pa})
$$

The Eye model is designed to best represent the real cornea by taking into account the typical eye geometry, Poisson ratio, Young's modulus, and maximum load pressure. All of the parameter values are listed in Table 1. It is important to note that in our case we used the averaged value of the determined Young's modulus that is $0.207 \mathrm{MPa}$, and the material parameter of the "ideal" artificial cornea with a constant Poisson ratio of 0.48 . In order to achieve as close as possible set values and to ensure the universality of its use, multiple materials and procedures of manufacturing of the artificial cornea have been realized. [23], [24].

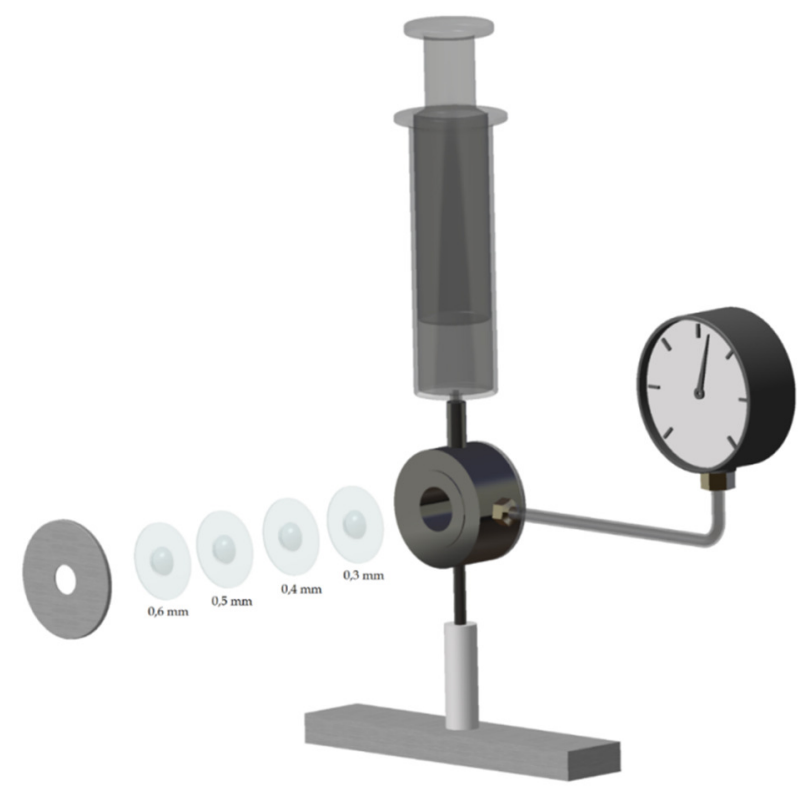

Fig.1. Overall setup of the developed standard for calibration and testing of non-contact eye tonometers [23].

The artificial cornea is one of the crucial parts of the described standard as it transmits the pressure generated from the piston via liquid to the tonometer. It also influences the indicated pressure by the tonometer by its mechanical, optical, and material properties. Therefore, its characterization is important to be able to create a reliable, reproducible and precise non-contact tonometer standard. The artificial eye cornea has the shape of a circular disc made of silicone based material, which is a replaceable element of 
the eye model. It can be observed in Fig.1. and Fig.2. The shape, surface structure and geometry of the artificial cornea are achieved by silicon molding. Mechanical properties of a silicone based artificial cornea, using exactly the same thickness as its human equivalent, are different in direct comparison. Young's modulus of silicone based materials is $(0.1-1.4) \mathrm{MPa}$. As can be observed it is noticeably larger in comparison to human cornea's Young's modulus that is from $0.054 \mathrm{MPa}$ to $0.359 \mathrm{MPa}$ [20], [21], [23], [24].

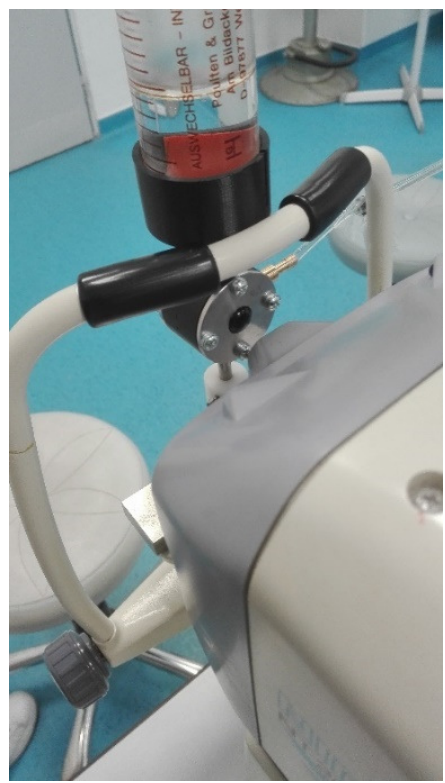

Fig.2. Developed standard's eye model with the artificial cornea used during non-contact eye tonometer measurements.

Table 1. Ideal cornea material parameters.

\begin{tabular}{|l|l|}
\hline \multicolumn{1}{|c|}{ Parameter } & \multicolumn{1}{c|}{ Values } \\
\hline Cornea diameter (CD) & (10.50 to 12.75$) \mathrm{mm}$ \\
\hline Anterior cornea curvature (ACC) & (7.06 to 8.66$) \mathrm{mm}$ \\
\hline Central cornea thickness (CCT) & (512 to 569.5$) \mu \mathrm{m}$ \\
\hline Poisson ratio & 0.48 \\
\hline Young's modulus & $(0.054$ to 0.359$) \mathrm{MPa}$ \\
\hline Max. loading pressure & $4.67 \mathrm{kPa}(35 \mathrm{mmHg})$ \\
\hline
\end{tabular}

*Source $[20,21]$

\section{RESULTS}

The differences mentioned can be overcome by modifying the thickness of the mold pressed cornea. To determine the artificial cornea thickness that would compensate the material properties' differences, a series of measurements with varying thicknesses were conducted. Specifically the thicknesses of the silicone cornea that were investigated were $0.3 \mathrm{~mm}, 0.4 \mathrm{~mm}, 0.5 \mathrm{~mm}$, and $0.6 \mathrm{~mm}$. The results of these measurements are presented in Fig.3. Each point on the graph represents an average of 12 measurements done for each respective pressure.

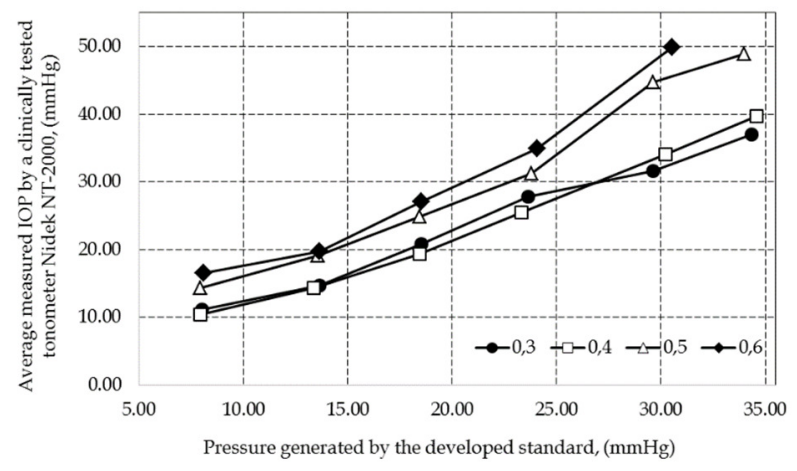

Fig.3. Comparison of different artificial cornea thicknesses and their effect on the IOP measurement by a clinically tested noncontact tonometer Nidek NT2000 [23].

Fig.3. shows how the set pressure by the developed standard corresponds to the indicated IOP pressure by a clinically tested non-contact tonometer Nidek NT2000. This clinical test was done in accordance with the standard ISO 8612 [22], [23]. As can be seen the smallest differences throughout the whole measurement range between the tonometer device and the developed reference were achieved by the $0.4 \mathrm{~mm}$ artificial cornea. The use of higher thicknesses had caused a more significant deviation and the decrease of thickness beneath the $0.3 \mathrm{~mm}$ had shown no benefit but has caused instability at higher pressures. It should be noted that the $0.7 \mathrm{~mm}$ thick cornea has caused the absence of an applanation and therefore no data could be measured. These findings led us to use the $0.4 \mathrm{~mm}$ thickness in further measurements.

In order to use the developed device as a standard for calibration of non-contact eye tonometers, an extensive testing is required to obtain the key metrological parameters of the device that will result in the determination of its uncertainty. This process is essential and will decide if the device has the capability of becoming a standard.

A total of two tests were conducted on the developed universal standard device. The initial testing consisted of a routine measurement procedure that is used in ophthalmological practice on commonly used devices and in typical environmental condition. The devices that were used in this initial test were a non-contact and a rebound tonometer - NIDEK NT2000 and Rebound ICARE, respectively. The purpose of these initial measurements was to validate the function of the standard and to define basic metrological parameters as the repeatability and stability of the generated pressure of the device transmitted by the $0.4 \mathrm{~mm}$ thick artificial cornea. This was done in the pressure points of $3 \mathrm{kPa}(22.502 \mathrm{mmHg})$ and $5 \mathrm{kPa}(37.503 \mathrm{mmHg})$.

The generated values and the measured values by the noncontact tonometer at $3 \mathrm{kPa}$ differ in average by $0.835 \mathrm{mmHg}$ $(111.324 \mathrm{~Pa})$. As for the rebound tonometer the differences in average were $1.298 \mathrm{mmHg}(137.052 \mathrm{~Pa})$. For the higher generated pressure of $5 \mathrm{kPa}$ the differences during measurements with non-contact tonometer were $0.497 \mathrm{mmHg}(66.261 \mathrm{~Pa})$ and $1.653 \mathrm{mmHg}$ (220.381 Pa) for the rebound tonometer. These results are based on a series of more than 140 measurements in total. 
Table 2. Result from test measurement with the developed standard and non-contact tonometers Nidek NT2000.

\begin{tabular}{|c|c|c|}
\hline \multicolumn{2}{|c|}{ DEVICES } & $\begin{array}{c}\text { DIFERENCE } \\
\text { (DEVELOPED } \\
\text { STANDARD - NIDEK } \\
\text { NT2000) } \\
\text { DEVELOPED }\end{array}$ \\
\hline $7.95 \mathrm{mmHg}$ & $10.43 \mathrm{mmHg}$ & $-2.48 \mathrm{mmHg}$ \\
\hline $13.35 \mathrm{mmHg}$ & $14.36 \mathrm{mmHg}$ & $-1.01 \mathrm{mmHg}$ \\
\hline $18.45 \mathrm{mmHg}$ & $19.37 \mathrm{mmHg}$ & $-0.92 \mathrm{mmHg}$ \\
\hline $23.33 \mathrm{mmHg}$ & $25.51 \mathrm{mmHg}$ & $-2.18 \mathrm{mmHg}$ \\
\hline $30.23 \mathrm{mmHg}$ & $34.07 \mathrm{mmHg}$ & $-3.84 \mathrm{mmHg}$ \\
\hline $34.58 \mathrm{mmHg}$ & $39.70 \mathrm{mmHg}$ & $-5.12 \mathrm{mmHg}$ \\
\hline
\end{tabular}

* Each measured value is the average of 12 measurements.

Table 3. Uncertainty budget of the developed standard.

\begin{tabular}{|l|l|l|l|}
\hline \multicolumn{1}{|c|}{$\begin{array}{c}\text { UNCERTAINTY } \\
\text { COMPONENT }\end{array}$} & TYPE & \multicolumn{1}{|c|}{ VALUE } & DISTRIBUTION \\
\hline Reproducibility & $\mathcal{U}_{\mathrm{A}}$ & $0.016 \mathrm{mmHg}$ & ----- \\
\hline Time determination & $\mathcal{U}_{\mathrm{B}}$ & $0.001 \mathrm{mmHg}$ & Uniform \\
\hline Pressure generation & $\mathcal{U}_{\mathrm{B}}$ & $0.200 \mathrm{mmHg}$ & Normal \\
\hline $\begin{array}{l}\text { Distance between eye } \\
\text { and nozzle }\end{array}$ & $\mathcal{U}_{\mathrm{B}}$ & $0.005 \mathrm{mmHg}$ & Uniform \\
\hline $\begin{array}{l}\text { Artificial cornea } \\
\text { thickness }\end{array}$ & $\mathcal{U}_{\mathrm{B}}$ & $0.600 \mathrm{mmHg}$ & Uniform \\
\hline $\begin{array}{l}\text { Mechanical properties of } \\
\text { artificial cornea }\end{array}$ & $\mathcal{U}_{\mathrm{B}}$ & $0.800 \mathrm{mmHg}$ & Uniform \\
\hline Effects of environment & $\mathcal{U}_{\mathrm{B}}$ & $0.100 \mathrm{mmHg}$ & Uniform \\
\hline Air jet position & $\mathcal{U}_{\mathrm{B}}$ & $0.005 \mathrm{mmHg}$ & Uniform \\
\hline
\end{tabular}

The second testing was done with the non-contact tonometer Nidek NT2000 that was clinically tested in accordance with ISO 8612 [22], [23]. The results of the clinical test have shown that the device is suitable to be used for eye tonometry measurements. As this device was deemed to be in accordance with the ISO standard, the comparison with the developed standard was carried out to see the possible differences. The stability of the generated pressure and repeatability of the standard was established before, so the comparison test focused on the possible differences throughout the IOP range from around $8.00 \mathrm{mmHg}$ up to about $34.60 \mathrm{mmHg}$. As can be seen from Table 2. the differences varied with set pressure in the developed standard. It is worth pointing out that the highest differences were found on both ends of the range $-5.12 \mathrm{mmHg}$ at set pressure of $34.58 \mathrm{mmHg}$ (indicated by the developed standard) and $-2.48 \mathrm{mmHg}$ at set pressure of $7.95 \mathrm{mmHg}$ (indicated by the developed standard).

Uncertainty determination is one of the crucial indicators of standard limits and capabilities by means of quantifying each individual factor affecting the generated value.

The overall uncertainty budget that list the most significant factor affecting the standard is based on the principles used within the developed standard and the conditions under which it should be routinely used. For our specific case we have taken into account the following influential factors that have the highest probability of affecting the developed standard: distance between eye and air source (nozzle), time determination, pressure generation, mechanical properties of artificial cornea, effects of environment (temperature, humidity), and air jet position. The detailed values of the listed influential factors together with the developed standard reproducibility can be seen in Table 3 .

\section{DISCUSSION}

The presented test measurements have been conducted in order to determine the key metrological properties of the newly developed standard. The tests have determined the reproducibility and stability of the pressure generation of the standard, as well as the quantification of the effects of most influential factors on the measurements carried out with this device. Based on the principles that the developed standard and non-contact tonometer devices make use of, the list consist of the following effects: distance between eye and air source (nozzle), time determination, pressure generation, artificial cornea thickness, mechanical properties of artificial cornea, effects of environment (temperature, humidity), and air jet position. As can be seen from Table 3. the most significant contributions are made by artificial cornea thickness and mechanical properties $(0.6 \mathrm{mmHg}$ and $0.8 \mathrm{mmHg}$ respectably). This indicates that an increased attention should be given to these parameters. At present the artificial cornea thickness was investigated and the results can be seen in Fig.3. These investigations compared the set pressure (measured by a calibrated pressure gauge) by the developed standard with the indicated IOP pressure by a clinically tested (in accordance with ISO 8612) non-contact tonometer Nidek NT2000. The results have shown that the smallest differences throughout the whole measurement range between the tonometer device and the developed reference were achieved by the $0.4 \mathrm{~mm}$ artificial cornea. As the normal thickness of human cornea is from $0.512 \mathrm{~mm}$ to $0.569 \mathrm{~mm}$, there is a need for the improvement of the artificial cornea properties. The mechanical properties of the artificial cornea have been based on data provided by our preliminary experiments. These experiments are the subject of further research. The value of the corresponding uncertainty contribution is a qualified estimation based on this data.

Taking into account the basic principles of the developed standard presented in equation (3), the measurements conducted by this device are traceable to the basic SI unit 
(specifically $\mathrm{Kg}$ ). It can be also stated that the described standard has a measurement uncertainty of $1.02 \mathrm{mmHg}$ $(k=1)$. In conclusion this device has the potential to become traceable and a universal standard for control and calibrations of non-contact eye tonometers that is currently not available.

\section{CONCLUSION}

The presented paper has shown a clear need for an independent standard with defined measurement uncertainty and established traceability for the purpose of non-contact tonometer control and calibration. The initial prototype of this portable potentially universal standard was presented together with initial test results on non-contact and contact (rebound) tonometers. On the basis of the discussion it can be seen that it is necessary to compare the properties of the artificial cornea with the properties of the human cornea. This will enable to provide a reliable and traceable calibration option for eye tonometers.

\section{ACKNOWLEDGMENT}

This research is part of the inTENSE (16RPT03) project that was done thanks to the EMPIRE initiative which is cofunded by the European Union's Horizon 2020 research and innovation programme and the EMPIR participating states.

The authors would like to furthermore thank the Faculty of Mechanical Engineering of the Slovak University of Technology in Bratislava, the Czech Metrology Institute, the Department of Ophthalmology, Faculty of Medicine, Comenius University in Bratislava, Hospital Ružinov, the grant agency APVV projects number (15-0295 and 18-0066); VEGA projects number (1/0098/18 and 1/0556/18) and KEGA projects number (065STU-4/2018, 023STU-4/2020, 019STU-4/2020 and 014STU-4/2020) for their support.

\section{REFERENCES}

[1] Thylefors, B., Negrel, A.-D. (1994). The global impact of glaucome. WHO Bulletin OMS, 72, 323-326.

[2] World Health Organization. Blindness: Vision 2020 The Global Initiative for the Elimination of Avoidable Blindness, Fact sheet $\mathrm{N}^{\circ} 213$. http://www.who.int/ mediacentre/factsheets/fs213/en/.

[3] Tonnu, P.A., Ho, T., Sharma, K., White, E., Bunce, C., Garway-Heath, D. (2005). A comparison of four methods of tonometry: Method agreement and interobserver variability. British Journal of Ophthalmology, 89 (7), 847-850.

[4] Jansson, U., Brautaset, R., Cervino, A., Nilsson, M. (2012). A comparison of the canon TX-20PTM noncontact tonometer and pachymeter in healthy eyes. International Journal of Ophthalmic Practice, 3 (3), 96-102.

[5] Tranchina, L., Lombardo, M., Oddone, F., Serrao, S., Schiano Lomoriello, D., Ducoli, P. (2013). Influence of corneal biomechanical properties on intraocular pressure differences between an air-puff tonometer and the Goldmann applanation tonometer. Journal of Glaucoma, 22 (5), 416-421.
[6] Anton, A., Neuburger, M., Bohringer, D., Jordan, J.F. (2013). Comparative measurementof intraocular pressure by Icare tonometry and Airpuff tonometry in healthy subjects and patients wearing therapeutic soft contact lenses. Albrecht von Gracees Archiv für Ophthalmologie, 251 (7), 1791-1795.

[7] Wei, W., Fan, Z., Wang, L., Li, Z., Jiao, W., Li, Y. (2014). Correlation analysis between central corneal thickness and intraocular pressure in juveniles in northern China: The Jinan city eye study. PLoS One, 9 (8), 104842.

[8] Garcia-Resua, C., Pena-Verdeal, H., Minones, M., Giraldez, M.J., Yebra-Pimentel, E. (2013). Reliability of the non-contact tono-pachymeter Tonopachy NT$530 \mathrm{P}$ in healthy eyes. Clinical and Experimental Optometry, 96 (3), 286-294.

[9] Fujimura, F., Kamiya, K., Fujiwara, K., Shoji, N., Shimizu, K. (2013). Repeatability and reproducibility of measurements using a NT-530P noncontact tono/pachymeter and correlation of central corneal thickness with intraocular pressure. BioMed Research International, 2013 (1), 370592.

[10] Ogbuehi, K.C. (2006). Assessment of the accuracy and reliability of the Topcon CT80 non-contact tonometer. Clinical and Experimental Optometry, 89 (5), 310314.

[11] Farhood, Q.K. (2013). Comparative evaluation of intraocular pressure with an air-puff tonometer versus a Goldmann applanation tonometer. Clinical Ophthalmology, 7 (1), 23-27.

[12] Tamcelik, N., Atalay, E., Cicik, E., Ozkok, A. (2015). Comparability of Icare pro rebound tonometer with Goldmann Applanation and noncontact tonometer in a wide range of intraocular pressure and central corneal thickness. Ophthalmic Research, 54 (1), 18-25.

[13] Kuchynka, P. a kol. (2016). Oční lékařství 2. (Ophtalmology 2.). Prague: Grada Publishing, ISBN 978-80-247-5079-8.

[14] Synek, S., Skorkovska, S. (2014). Fyziologie oka a vidění 2. (The Physiology of Eye and Vision 2.). Prague: Grada, ISBN 978-80-247-3992-2.

[15] Hornova, J., Baxant, A. (2013). Současné možnosti měření nitroočního tlaku (Current possibilities of intraocular pressure measurement). Česká a slovenská oftalmologie, 69 (4), 175-180.

[16] Bureau International des Poids et Mesures (BIPM). (2006). Le Système international d'unités (The International System of Units (SI)). 8th edition, ISBN 92-822-2213-6.

[17] Hucko, B., Kucera, L., Duris, S., Pavlasek, P., Rybar, J., Hodal, J. (2020). Modelling of cornea applanation when measuring eye pressure. In Current Methods of Construction Design: Proceedings of the ICMD 2018. Springer, 327-332.

[18] Kolin, J. (2007). Oční lékařství 2 (Ophtalmology 2). Prague: Karolinum, ISBN 978-80-246-1325-3. 
[19] Masek, P., Cholevik, D., Nemcansky, J. (2014). Oftalmologie a diagnostické metody a prístroje voftalmologii (Ophthalmology, Diagnostic Methods and Instruments in Ophthalmology). Ostrava: University of Ostrava, ISBN 978-80-7464-569-3.

[20] Bekesi, N., Dorronsoro, C., de la Hoz, A., Marcos, S. (2016). Material properties from air puff corneal deformation by numerical simulations on model corneas. PLoS One, 11 (10), e0165669.

[21] Simonini, I., Pandolfi, A. (2016). The influence of intraocular pressure and air jet pressure on corneal contactless tonometry tests. Journal of the Mechanical Behaviour of Biomedical Materials, 58, 75-89.

[22] International Organisation for Standardization. (2009). Ophthalmic instruments - Tonometers. ISO 8612:2009.
[23] Rybář, J. (2019). Vývoj metód pre zabezpečenie nadväznosti meradiel vnútroočného tlaku (Development of methods for traceability assurance of intraocular pressure measuring instruments). Dissertation thesis, Slovak University of Technology in Bratislava, Faculty of Mechanical Engineering.

[24] Zatkalíková, V., Markovičová, L., Škorvanová, M. (2017). Corrosion behaviour of electropolished AISI 316L austenitic biomaterial in physiological solution. IOP Conference Series: Materials Science and Engineering, 266, 012016.
Received March 24, 2020

Accepted August 3, 2020 